posed priority conservation strategies surrounding: (1) species and research, (2) habitat and landscape, (3) community engagement and (4) law enforcement and policy development. On the second day, working groups prioritized and outlined activities needed to achieve each strategy, including the delineation of timeframes, responsible organizations, outputs, and methods to monitor success. Subsequently, an updated action plan was published in March 2020 (Carstens et al., 2020, Cape Parrot and Mistbelt Forest Conservation Action Plan, cpsg.org/sites/cbsg.org/files/documents/Cape\% 2oParrot\%20and\%2oMistbelt\%2oForest\%20Action\%2oPlan \%20202003.pdf), defining the vision, scope, goals and targets to conserve the Cape parrot, and identifying 90 actions needed to achieve this. In recognition of the central role of habitat protection, the plan focuses jointly on the conservation of the species and its associated forests, including the ambitious target of doubling the area of Southern Mistbelt forest under formal protection in 10 years.

With the updated action plan published, and an Action Group formed, stakeholders are working collaboratively towards the vision of a thriving population of Cape parrots acting as a flagship species for the protection and recovery of indigenous forests in South Africa, for the shared benefit of people and nature.

JESSICA LEAVER (๑ orcid.org/0000-0003-1431-7298), Kate Carstens, Kirsten Wimberger and Clare Padfield (○ orcid.org/0000-0002-8729-4296) Wild Bird Trust, Hogsback, South Africa

E-mail jess@wildbirdtrust.com

Rowan Martin World Parrot Trust, Hayle, UK

ColleEn Downs (๑ orcid.org/0000-0001-8334-1510) and PRESHNEE SINGH University of KwaZulu-Natal, Pietermaritzburg, South Africa

HaRriet DAVIes-Mostert IUCN Species Survival Commission Conservation Planning Specialist Group, and Endangered Wildlife Trust, Johannesburg, South Africa

KerRYN MorRISON IUCN Species Survival Commission Conservation Planning Specialist Group, Endangered Wildlife Trust, Johannesburg, South Africa, and International Crane Foundation, Baraboo, USA

AnNa Young Otterbein University, Westerville, USA

MeLISSA Howes-Whitecross BirdLife South Africa, Johannesburg, South Africa

SHAun WiLKInson Montecasino Bird Gardens, Johannesburg, South Africa

\section{Last chance to prevent the extinction of the Chinese pangolin}

The Chinese pangolin Manis pentadactyla occurs from Nepal eastwards and across southern China. It is believed to be one of the most heavily poached and trafficked mammals in Asia (Challender, 2011, Traffic Bulletin, 23, 92-93). The species is categorized as Critically Endangered on the IUCN Red List, with a decline of more than $80 \%$ suspected over three generations because of hunting and poaching for local and international use, with extirpation of the species in some areas (Challender et al., 2019, dx.doi.org/10.2305/IUCN.UK. 2019-3.RLTS.T12764A168392151.en).

Public and government awareness of the need to protect the Chinese pangolin is improving, and the species has recently been receiving increased attention in both traditional and online media. In June 2020 the Chinese government upgraded all pangolins to the first-class level of protection for species in China, and removed them from the Chinese Pharmacopoeia. Six national parks have been established since 2014 to protect biodiversity cover $34,585 \mathrm{~km}^{2}$ of the pangolin's distribution range in China (China Green Times, 2019, forestry.gov.cn/main/ 72/20191018/100213014982208.html).

The Pangolin Conservation and Research Centre of the National Forestry and Grassland Administration was established in July 2020 by the Chinese government. It is responsible for rescuing injured or seized live pangolins, conservation biology research, and developing new breeding techniques for ex situ conservation and restoration of the species to the wild. In this context, staff of the Centre rescued a Chinese pangolin and released it into the wild in July (China Global Television Network, 2020, news.cgtn.com/news/2020-07-08/ Rescued-Chinese-pangolin-released-back-into-wildRVSeozzetG/index.html).

Additional measures are required for the protection of all pangolin species in China, including environmental education, anti-poaching mechanisms, and a conservation action plan for the Chinese pangolin. Any action plan for the species will need to include improved habitat connectivity, reforestation (it is a forest specialist), and study of its biology and ecology, which are poorly known.

YAN HUA (๑ orcid.org/0000-0001-8316-3937) and

SHICHAO WeI (○ orcid.org/0000-0001-9151-1356)

Guangdong Provincial Key Laboratory of Silviculture, Protection and Utilization, Guangdong Academy of Forestry, Guangzhou, China

HENG BAO College of Wildlife and Natural Protected Areas, Northeast Forestry University, Harbin, Heilongjiang, China 
SHIBAO WU (○ orcid.org/0000-0003-4683-4919) College of Life Sciences, South China Normal University, Guangzhou, China, and IUCN Species Survival Commission Pangolin Specialist Group, Zoological Society of London, London, UK E-mailwushibao@163.com

\section{Critically Endangered subpopulation of Irrawaddy dolphin in central Philippines may lose its habitat to large-scale development project}

The Irrawaddy dolphin Orcaella brevirostris is a rangerestricted, facultative freshwater species that inhabits coastal, estuarine and freshwater habitats in disjunct populations from India to South-east Asia. The Iloilo-Guimaras Straits subpopulation is one of three known O. brevirostris subpopulations in the Philippines and the second to be declared Critically Endangered (Dolar et al., 2018, dx.doi.org/10. 2305/IUCN.UK.2018-2.RLTS.T1230959 78A123095988.en). This subpopulation of $13-25$ individuals was discovered in 2007, and is believed to be in decline. This decline is likely to be exacerbated should the Philippine government pursue plans to construct the Panay-Guimaras-Negros bridges under their 'Build, Build, Build' agenda to boost interconnectivity for economic development.

A feasibility study of the proposed bridges stated that the construction phase would have few significant effects on the marine fauna. However, the proposed bridges will affect an Important Marine Mammal Area and the known range of this O. brevirostris subpopulation (Fig. 1). Specifically, the potential bridge alignment $\mathrm{D}$ directly bisects the species' core habitat (de la Paz et al., 2020, Raffles Bulletin of Zoology, 68, 562-573). We know from the case of the Indo-Pacific humpback dolphin Sousa chinensis in the Pearl River Delta affected by the Hong Kong-Macau-Zhuhai bridge (Karzmarski et al., 2016, Advances in Marine Biology, 73, 27-64) that the cumulative effects of existing threats and extensive construction in the species' habitat will have irreversible impacts on its long-term survival.

The Iloilo-Guimaras Straits subpopulation of O. brevirostris already faces grave threats from bycatch, collision with boats, illegal fishing, and habitat degradation. During the construction phase of these bridges we would expect an increase in noise pollution from pile driving and the ferrying of materials, and consequent negative effects on the bio-acoustic behaviour of the dolphins and an increased risk of collisions with boats. We expect long-term effects, such as sediment bed changes and scouring, changes in water movement and current, and changes in prey dynamics, to affect the local environment even after the bridges are built. In time, such effects will be felt by local residents who rely on these straits for their livelihood.

Yet, there is still hope. On 6 August 2020, government officials announced the shelving of the Guimaras-Negros segment of this large-scale infrastructure project, citing the presence of mangroves and dolphins. This announcement followed a public outcry that questioned the validity of the preliminary assessment as it had ignored the presence of Irrawaddy dolphins within the proposed construction sites. However, this change offers only temporary relief to this subpopulation, considering the extensive threats to its long-term survival. We must, collectively, continue to give

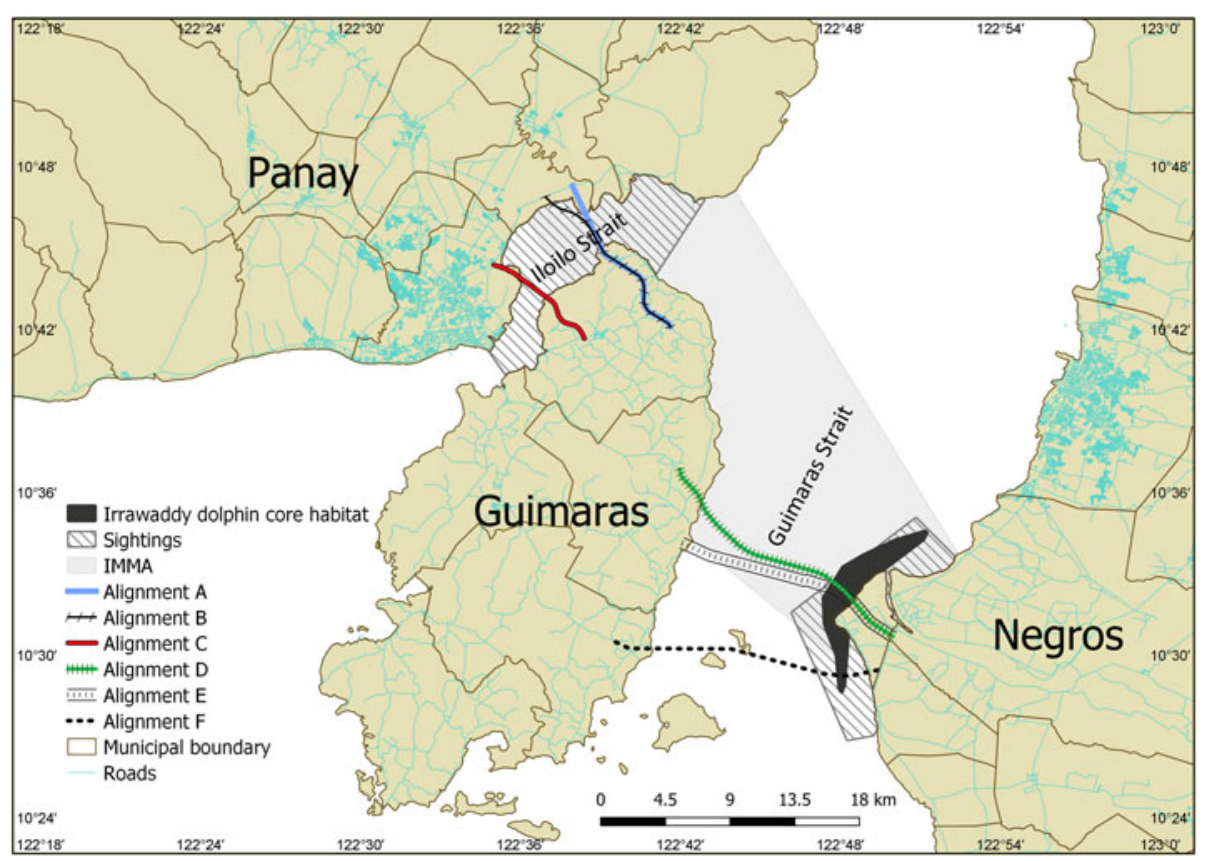

FIG. 1 The known range of the Iloilo-Guimaras Straits subpopulation of the Irrawaddy dolphin Orcaella brevirostris in the central Philippines includes parts of the Iloilo and Guimaras Straits. An ambitious project to construct bridges connecting the islands of Panay, Guimaras and Negros would bisect a recognized Important Marine Mammal Area (IMMA) and the core habitat of this Critically Endangered subpopulation of $O$. brevirostris. This map summarizes all known spatial data on the subpopulation. The alignments indicate the different bridge positions being considered. Important Marine Mammal Area boundaries are from Marine Mammal Protected Area Task Force (2020, marinemammalhabitat.org). 